\title{
An Extended Study on Introducing Social Work into Petition Practice
}

\author{
Wei $\mathrm{MU}^{1}$ \\ ${ }^{1}$ Yunnan University of Finance and Economics
}

Keywords: Complaint letter and visit, Social work practice possibility.

\begin{abstract}
China is now undergoing profound systematic and social transitions. Chinese society is getting stratified with more and more complicated social problems. Therefore, traditional ways to deal with people's letters and calls, which depends on the ideological and political work as well as on the government administration, is not able to meet the requirements of the social development. With the popularization of professional social work, the social work practice mode has been widely put into use. The thesis focuses on the internal relationship between the ways to deal with people's letters and calls and social work practice for the purpose of providing some practical suggestions to enrich the theoretical system of the ways to deal with people's letters and calls and to improve social work mode.
\end{abstract}

\section{Introduction}

As the traditional mechanism to solve disputes in China, petition has played an important role in the process of settling social conflicts, maintaining social stability and promoting the development of social economy. However, at the stage of system transformation and society reforming, China is experiencing rapid changes not only in terms of economy but also in terms of social levels and structures. Social levels are diversified and social conflicts are more obvious: the imbalance in benefit distribution has increased the conflict of interests; under the limitation of economic development and policies, the different interest appeals of different social group can hardly be met, which gave rise to new conflicts and problems. In such social change, petition letter should be practiced under the guidance of people-oriented outlook of scientific development so as to enrich the theoretical understanding of social problem solving and develop the technology to address the petition letter to meet the requirement of the new era.

With the development of social environment, the traditional thinking of using administrative methods as the main approach and taking a compulsory attitude towards the petition work is no longer suitable for the demand of current mass work. After the Regulations of Petition Letters (the newest version) is issued, the traditional petition work is modified by rules and regulations, among which the most prominent ones are: firstly, the petition channels are diversified, which means that the viewpoints of the government and the public are mutually accessible and the bottom-up channel of public demand expression is possible. In so doing, the social situations and public ideas can be understood on time and the social conflicts will be settled; secondly, the content of innovating petition work system is added in the regulation to improve the efficiency and effect of petition; thirdly, the content of maintaining the order of petition is added to protect the legal benefits of the petitioners and maintain the social stability in a better way; finally, the content of petition responsibility is added to encourage the public to reflect problem and to solve the problems in a reasonable manner. From the content 
change of the new version, we can see that, the regulation of petition letter has proposed new requirements on the petition at a new era, which include the emphasis of solving disagreements among the people rather than just transferring or relieving them. The solving of these disagreements highlights the realization of institution responsibility system on the one hand; on the other hand, it also highlights the idea transformation of the workers in petition field and the practical function of petition institutions for people. They should conduct the petition under the idea of "helping people" so as to coordinate social resources. It is important to prevent petition conflicts and disputes at their origin so as to establish investigation systems which will focus on the petitions on their origin.

Regulations of Petition Letters are the important basis to solve the petition, and they are also the modifications of traditional petition work. But what are the drawbacks of petition system? Firstly, it is obvious that the guiding ideas of the traditional petition work are that it tries to solve problems under the premise of country-first. The top-down thinking is mainly reflected in the adoption of ideological and political education as well as administrative methods and the lack of understanding of the petitioners. However, with the transformation of planned economy to market economy, country, group and individual are equally protected by the law. The practical situation of petition work has proposed more requirements on questions such as "what the petitioners need? How to influence petitioners effectively? And how to protect the results of petition?" Petition work has to change its idea, update its technology and use measures and methods in a comprehensive way; secondly, we can see from the content of regulation that the traditional petitions were being done from the perspective of ideology and politics with the aim to relieve disagreements among people. With petition institutions as the transfer station of disagreement, many petitions cannot be solved effectively and facts such as intercepting petition letters by the relevant institutions were not uncommon; thirdly, in terms of the knowledge background of workers in the field of petition, many of them were majored in administration, laws, Chinese and so on. Workers of sociological background and social work background are rare. The vocational training is more about ideological and political knowledge and laws rather than knowledge learning and technical competence cultivation of psychological therapy, interpersonal communication, social survey, community competence building and so on, which leads to the unicity of investigation methods in petition work and the limitation of solving methods of petition work. Due to the fact that petitions have its origin in the complex social life, the handling of it cannot be based solely on the application of knowledge of administrations and laws. It requires that the dispute handlers have to be equipped not only with knowledge of laws and administrations but also competence to communicate with others, to identify social conflicts and some other competence in terms of social work.

As for the responsibilities petition work, establishing warning system should be combined with solving disputes. On the one hand, in order to solve the disputes reasonably, the communication should be established on the basis that both parties are following the regulations and the dialogue should be finished in a fair and equal manner by following certain administrative or legal procedures. However, many previous petition works were solved without the communication between both parties and the guidance of the social regulations. The functions such as coordination and supervision of petition have not been fully realized. As a result, some rights of the petitioner are ignored and long-term petition.Social public crisis is on the rise as a result of the diversified social levels, the great gap between different levels, the increase of population and the lack of resources. Recently, emergent group incidents happened 
frequently. Land expropriation, cities building demolition, environment protection, restructure and bankruptcy of companies and law suits are all the main points in petition work, which have proposed new requirements on petition work. The construction of a harmonious socialist society requires not only the openness of petition channel but also the establishment of warning systems for social emergent incidents, which in turn requires a deep investigation of petition cases. For example, in Yuqing county of Guizhou province, in addition to the traditional petition channels, the blogs of the governor is also started to communicate with netizens in a pen manner; in order to construct the comprehensive petition channel of "Sunshine petition", governments at lower levels have established the petition office and have identified the specific responsibility of each petition case. 69 villages or communities have established their "mass work office" and 1779 groups have started the "mass work team" to facilitate the petition work, reflect problems and solve disputes of the public in the neighborhood.

Fifthly, the target of petition works are from different social levels and the handling of petition work should be done according to the specific conditions. What problems can be solved through petition work and what problems are out of the scope of petition work should be identified. For example, in many cases of petition, some individuals tried to express their feelings through petition and they regarded workers of petition office as the psychologist. Similar cases cannot be fully solved by the traditional work method and they require that new models should be established to become more individualized, softer and more humanistic. For example, in Yima city of Henan province, mass work unit is established base on the previous petition institution. Cases of civil institution and labor social security institution are integrated to be handled by institutions such as law service office, communication room, mass activity room, social situation and public idea room, financial help room and some other service units. The transformation in terms of institution is much suitable for the current situation of diversification of petition target and cases.

In the traditional process of solving petition work, the accumulation of experience and conventions was the main channel to obtain the work methods and techniques of petition work. However, experience and conventions can only give rise to some theoretical systems, which should be combined with technical methods to meet the demand of petition work. Currently, the applying of professional theories to petition practices is rare. With the development of social work researches and the process of professionalization, the current theoretical basis and practice models is useful for expanding the theories and methods of petition works. Although petition is practical in nature, its practices are composed of many techniques of work. The selection of methods will directly influence the efficiency of petition work. This section will discuss the improvement of petition models in terms of the value, characteristics and models of petition work.

Disadvantaged group is a concept used to analyze the imbalance of social economic distribution and social rights distribution, the diaharmony and unreasonablity of social structure. The main body of disadvantaged group is the socially disadvantaged group. In academic circle, disadvantaged group is usually divided into two parts: the physiologically disadvantaged group and the socially disadvantaged group. The former group is thus classified due to its physiological characteristics such as age and illness; the latter is derived from social reasons such as lay-off and unemployment. In China, the disadvantaged group is mainly about the socially disadvantaged group, which is the result of social reasons. As a result, the social perspective should be attached with great importance. Social work belongs to the field social science, which highlights the 
researches and emphasis on the socially disadvantaged group and helps them solving daily problems such as the shortage of resources, the lost of rights, the inequality of society and the problems, conflicts and disputes derived from their own disabilities.

Petition work is the window through which the government can learn the society and it also plays the roles of supervision and information communication. In terms of the social benefit, it is a special system of right relief. Most of the petitioners are from the disadvantages group and most of them are located in a disadvantageous place because the lack of rights or the imbalance of right distribution. The disadvantaged people the petition workers are helping and the social worker are helping are to a large extent overlapped. And their aims are both "to promote the social equality, to highlight the reasonable distribution of social rights and to relieve the disadvantaged place of them through benefit distribution". Therefore, the focus on socially disadvantaged people in social work and the focus on right relief in petition work are in nature similar to each other. Right relief requires the disclosure of living situation of the disadvantage group to the authorized institution. As the window through which the government learns the public situation, petition work should focus on the disadvantage group so as to provide valuable suggestions for the policy-making by the government. In so doing, their interests will be maximized and the happening of social dispute and emergent mass incidents will be declined.

Firstly, social work practice is characterized as universal. Petition work and social work are all finished in social practice. The target of petition may be senior people, migrant workers, farmers without lands, laid-off workers and so on. Although their problems are different, the unified model established in social practice can be adopted to handle the problems. For example, adopting psychological and social therapy to deal with the extreme actions in the petition process can relieve the extreme emotions of the target to certain extent, which is suitable for the settling of the petition cases. Secondly, the social work practice is intermediary in nature. On the one hand, it is theoretical to a large extent while on the other hand, it is practical obviously. The perfection of petition models requires that the experiences drawn from the petition cases should be abstracted to the level of theories. The abstracting process should be processed in certain scientific theoretical framework and the betweenness of the social work can meet the demand of theoretical development of petition work. Thirdly, social work practice is professional to a large extent. With its standard ethical regulations, professional techniques and methods, social work practice is widely used in social service and social management. As one of the important parts of governmental mass work, petition is not only the window through which the disputes of involved individuals, families, groups, organizations and communities can be solved but also one part of social management which is useful for integrating social resources such as governmental resources and civil resources, coordinating social relations, preventing and solving social problems. The professionality of social work is helpful for perfecting the petition models.

There are three basic models of social work practice: case work, group work and community work. The introducing of these three models into the petition work is useful for dividing the individual disputes and group disputes to a certain degree, solving social conflicts by integrating knowledge of psychology, sociology, public management and other fields, handling social disputes and emergent incidents by coordinating social resources and preventing social problems in a planned manner. In so doing, the social relations will be improved, social disputes will be decreased, the initiative in participating petition will be cultivated, the efficiency of petition will be increased and the problem-solving mechanism will be perfected. 
Firstly, case work is the individualized model which adopts the one-to-one communicating method to investigate the case in a deep manner. The special points of the case will be sorted out to solve the problem in a specific manner. Many of the petition targets are individuals such as the cases involving the personal privacy, especially the psychological problems. Case work aims not only at individuals but also vulnerable families such as families without house, laid-off families and poor families; these are also cases involving the extreme individuals who cannot be solved by ideological education or regulations and laws.

Secondly, group work refer to the method which has two or more people as its target and it is mainly composed of group activities and interactions between members of the group which are aimed at involving members in collective activities to obtain group experience. It deals with the relation between individuals, interpersonal relations and the relation between human and the environment. In petition work, cases are similar to each other because they are all facing with group problems. For example, due to the relatively low quality of employees of the enterprises and the shortage of legal awareness among them, behaviors go against the labor law and labor contract happened from time to time, which is also one the reasons that have increased the number of labor disputes in petition. Thirdly, community work takes communities as the basic carrier. Among the petition cases, some of them have community as their unit and these communities often have the same benefit requirement. Community work is a social work method which often has the community or all the members as its target. It settles the problems of communities and meets the requirements of the communities by organizing members to participate the group work in a planned manner. From the strategies of social work, regional development has community members as the target of service and the participators of the activities and tries to fully motivate the problem-solving competence of the community members.

\section{Conclusion}

By introducing the procedures and mechanism of the social work practice, the governmental and civil resources can be utilized reasonably. On the one hand, social work advocates adopting different work models when facing different targets so as to coordinate social resource and realize the aim of providing service to other in a better way. Petition involves complex social problems and the service targets are of different levels, vocations, age and so on. In dealing with petition problems, the mass work units should be established and personnel should be selected from units closely related with public interests to enhance the competence to coordinate and handle different problems; on the other hand, the service process of social work focuses not only on the solving of existing problems but also on the long-term information collection and problem prevention of the target. As a result, petition work should not only pay attention to the current problems but also establish warning mechanism. The government should select specific personnel to collect information on social situation and public ideas, to investigate the difficulties of the public, to strengthen the ability to coordinate and handling problems and to construct complete security mechanism so as to solve the social problems and disputes in their bud.

Perfecting petition practice from the perspective of social work is beneficial for maximizing the function of petition and promoting the professionalization of social work on the one hand; on the other hand, it also provides insights into the multi-disciplinary thinking and applications of the innovation of petition methods. 


\section{References}

[1] Wang Sibin. The Professionalization of Social Work in the System Transformation[J]. Journal of Beijing University of Science and Technology, 2006(1).

[2] Chen Jinsheng. An Analysis of Chinese Petition System from the perspective of Harmonious Society Construction[J]. Legal Forum, 2008(3).

[3] Wang Yamei. An Analysis of the Standardization of Chinese Petition System[D]. Master's thesis of Shanxi University in 2006, China's Excellent MA Thesis full-text database.

[4] Ying Xing. Petition Relief as the Special Administrative Relief [J]. Legal Forum. 2004,(3).

[5] Zhu Zuizin, Zhu Kongwu. Reflection on Rights: Petition System in Legal Order [J]. Studies In Law and Business, 2006(2). 